\title{
The effect of Urea on epigeic earthworm species (Eisenia foetida)
}

\author{
WONECA LONG ${ }^{1}$, ABDULLAH ANSARI ${ }^{2, \bullet}$, DIANA SEECHARRAN ${ }^{2}$ \\ ${ }^{1}$ Faculty of Earth and Environmental Sciences, University of Guyana, Georgetown, Guyana \\ ${ }^{2}$ Faculty of Natural Sciences, University of Guyana, Georgetown, Guyana. ^email: abdullah.ansari@uog.edu.gy
}

Manuscript received: 10 November 2017. Revision accepted: 16 December 2017.

\begin{abstract}
Long W, Ansari A, Seecharran D. 2017. The effect of Urea on epigeic earthworm species (Eisenia foetida). Cell Biol Dev 1: 46-50. Using chemical fertilizers in intensive agriculture has undoubtedly increased crop production but has adversely affected soil properties over a long period. The effects clearly could be seen in the soil environment and the soil organisms living in that ecosystem. This study was conducted to determine the effects of Urea on epigeic earthworm species (Eisenia foetida) in clay soil. A total of five doses of Urea were used i.e $50 \mathrm{mg} / \mathrm{kg}, 100 \mathrm{mg} / \mathrm{kg}, 150 \mathrm{mg} / \mathrm{kg}, 200 \mathrm{mg} / \mathrm{kg}$ and $250 \mathrm{mg}$. They were labeled T1, T2, T3, T4, and T5, respectively. A control group was also set up, and the treatment groups were replicated three times. The results indicated that adding Urea affected the soil's chemical properties in treatments inoculated with earthworms (Eisenia foetida). The adult earthworm population was $70 \%$ in control when compared to different treatment dosage of Urea $50 \mathrm{mg} / \mathrm{kg}(\mathrm{T} 1)-85 \%, 100 \mathrm{mg} / \mathrm{kg}(\mathrm{T} 2)-66.67 \%, 150 \mathrm{mg} / \mathrm{kg}$ (T3) $-68.34 \%, 200 \mathrm{mg} / \mathrm{kg}$ (T4)- $86.67 \%$ and $250 \mathrm{mg} / \mathrm{kg}$ (T5)- $51.67 \%$. The mortality percentage was minimal in treatments $\mathrm{T} 4$ and $\mathrm{T} 1$, whereas it was maximum in treatment T5 $(48 \%)$. A $250 \mathrm{mg} / \mathrm{kg}$ dose was the most toxic dose of Urea in the soil inoculated with earthworms. The results were significant at $\mathrm{p}=0.05$.
\end{abstract}

Keywords: Chemical fertilizer, earthworms, physicochemical, mortality, toxic

\section{INTRODUCTION}

The chemical fertilizer applied on agricultural land could affect the soil quality and the survival of soil organisms. Earthworms are a major component of soil fauna; the total population is approximately $60 \%$ of the macro-organisms in the soil. Earthworms are considered soil quality indicators because they respond and contribute to healthy soils. Their populations depend on several conditions related to soil quality, including $\mathrm{pH}$ and organic matter, resistant-waterlogged soil, compact, drought, or excessive sandy (Rani 2016). Agriculture is one of the most important economic activities in Guyana.

Along with other natural resource sectors, agriculture contributed 28\% of Guyana's total GDP in 2015 (World Bank 2016). However, many farmers have cultivated their land for rice production for over 15 years; therefore, the lands are thus exhausted and cannot replenish the nutrients needed for high yields efficiently. External agricultural inputs to the soil, such as chemical fertilizer and Urea, have maximized productivity and increased economic returns (Moonilall 2015). Urea is a very common chemical fertilizer used on farms in Guyana. However, researchers have found that nitrogenous fertilizers, such as Urea, are toxic to soil organisms.

Charles Darwin was one of the first people to recognize the value of earthworms in the soil. His research estimated that worm casting alone could provide 1/5 inch of new surface soil per acre of land (Darwin 1881). Earthworms have many important functions in the soil. They can be considered soil quality indicators because they are sensitive to their environment (Iordache and Borza 2010). Earthworms are very important to the soil; tunneling through the soil, drains the water, brings in oxygen, and creates space for plant roots. As worms till the soil, it becomes better aerated and more water absorbent and increases in fertility. Earthworms produce nitrogen, phosphorous, potassium, calcium carbonate, and many micronutrients in a form that all plants can use. They can also help to bring acid soil back to a more neutral $\mathrm{pH}$ over time (Ashiya et al., 2015). Their casts contain calcium carbonate (Tiwari 1993). They are very important in soil formation; the presence of earthworms is significant in maintaining the structure and function of the soil, particularly in agroecosystems (Abbirammy and Ross, 2013). The relationship between soil quality, earthworm abundance, and chemical fertilizers has long been the interest of researchers. The use of chemical fertilizers is one such factor. Different fertilizers are used in different doses on crop farms; they all contribute positively or negatively to earthworms.

The study carried out by Edward, and Lofty on the effect of fertilizer on earthworms shows that Urea applied over a long time can increase the earthworm population in the soil where maize is cultivated (Edwards and Lofty 2002). Additional studies agree with this finding that Urea can initially benefit the earthworm population, but the long-term effects are negative (Iordache and Borza 2010). Direct contact with Urea and the earthworm body is lethal even at very small concentrations. Therefore, Urea is classified as highly toxic (Abbirammy and Ross 2013). These studies indicate that nitrogenous fertilizers, such as Urea, can positively and negatively impact the earthworm population. One assumption is that nitrogen allows for faster production, which will cause organic matter to replenish into the soil faster, encouraging more worm 
activity. Another assumption is that a small urea concentration is not harmful to the earthworms, but higher concentrations are lethal (Rai et al. 2014).

This research was conducted to determine the effects of Urea, a nitrogenous fertilizer, on earthworms. It was important to determine if there is a significant relationship between the reproduction rate of the earthworms and the use of Urea in the soil. It was also oriented to determine what urea concentration is lethal to the worms in the soil. It would therefore help to regulate Guyana's agricultural policies concerning using Urea on farms. It will also alert the farmers about the effects of Urea on earthworms so that their practices can be adjusted accordingly.

\section{MATERIALS AND METHODS}

\section{Earthworm sampling and collection}

Earthworms (Eisenia foetida) were used in the experiment. The earthworms were collected from a farm in the study area $\left(6.7649^{\circ} \mathrm{N}, 58.0403^{\circ} \mathrm{W}\right)$ and identified by a specialist. The hand sorting method collected the adult earthworms from the soil (Valckx et al. 2011). Adult earthworms with a clitellum of relatively homogenous age structure were used for the experiment. The earthworms were collected before setting up the bins and kept in a soil substrate to be used for the test at a temperature of approximately $22 \pm 2^{\circ} \mathrm{C}$. The worms were washed with distilled water, and the excess water was removed by placing them on paper preceding their transfer to the bins. The weight of 60 earthworms was recorded, and the average was found to determine the approximate weight of the earthworms in each bin.

\section{The urea materials and treatment preparation}

Several recommendations were used to set up the experimental lab conditions (OECD 2015), (Rai et al. 2014), (Iordache and Borza 2010). A Completely randomized block design with three replications and six treatments was used. One control treatment and five treatment groups i.e $50 \mathrm{mg} / \mathrm{kg}$ (T1), $100 \mathrm{mg} / \mathrm{kg}$ (T2), 150 $\mathrm{mg} / \mathrm{kg}$ (T3), $200 \mathrm{mg} / \mathrm{kg}$ (T4) and $250 \mathrm{mg} / \mathrm{kg}$ (T5). The experiment was terminated after sixty days, and the recommended lab analysis was done.

The fertilizer used in the experiment was granular Urea. It was purchased from a local pet store. Non-transparent plastic bins with a holding capacity of $12 \mathrm{~kg}$ and a diameter of $25 \mathrm{~cm}$ were used on collected. The bins were thoroughly washed, punctured to allow infiltration, and finally appropriately labeled. Eighteen bins were used for the experiment ( 6 treatments $* 3$ replication $=18$ bins).

The clay soil was used in the experiment, collected from the study area, dried excess water, chipped to an appropriate size, and removed any excess debris. The $\mathrm{pH}$, TDS, organic carbon, nitrogen, phosphorus, and potassium were taken. A substrate of $5 \mathrm{~kg}$ of soil was added to each bin. Dried filtered cattle dung was also collected from a local farmer. $2.5 \mathrm{~g}$ of cattle dung was added to each of the bins. The soil and cattle substrate was thoroughly mixed and dampened with water. After two weeks, the soil amendment paddy shell was added to the mixture-top to loosen the soil and keep it moist. Twenty adult Red Earthworms were placed on the surface of the soil and cattle dung mixture, any worm that did not burrow into the soil after 15 minutes was then replaced with a healthy worm. The bins were then randomly distributed on a level table, and a thin mesh was placed over it to prevent the worms from escaping from the bins.

The bins were carefully observed for 6 days before the first application of Urea was made. Then, the Urea was dissolved in $100 \mathrm{~mL}$ of water and applied to the surface by spraying. According to the custom for such experiments, the bins were left open for one hour afterward. The bins were carefully observed during this time to ensure no worms escaped. After this period, Urea will be carefully weighed out and added to the bins based on the amount of urea calculation. Next, to calculate the amount of Urea needed for one treatment, dried clay soil was placed in a one-meter squared area to a height of ten centimeters, and the soil was then weighed. An estimate of the amount of soil to a depth of ten centimeters in one hectare was then made. Finally, the amount of Urea needed for the experiment was calculated using this estimate and the standard range of Urea used by crop farmers in Guyana, which is $65 \mathrm{~kg}-180 \mathrm{~kg} /$ hectare.

Urea was added to the containers three times; the first application was $50 \%$ of the dose of Urea. The next application was made three weeks after the first treatment, and the final application was made three weeks after the second. $25 \%$ of Urea was added both times. The dried and filtered garden cattle manure was used as food for the earthworms. The initial application of $2.5 \mathrm{~g}$ of cattle dung was added to each bin. Next, a $10 \mathrm{~g}$ was added two weeks later, and the last application was after four weeks with an additional $50 \mathrm{~g}$ to each container. The bins were carefully observed to see if any further food application was needed, but this was not necessary. The worms' activity was carefully observed. The mortality and number of juveniles were recorded every 15 days. The hand sorting technique counted the number of adults and the number of juveniles in each bin. After the $60^{\text {th }}$ day, the number of juveniles was counted twice for accuracy.

The experiment was terminated after 60 days. The live adult worm was then flushed with distilled water and weighed using a digital scale. The earthworms were then dried in an oven at a constant temperature of 45 to $50^{\circ} \mathrm{C}$ for 5 days. The dried worms were crushed, and the amount of Nitrogen, Phosphorous, and Potassium in the dried powdered worms was determined using the methods listed below. In addition, 60 questionnaires were prepared and distributed among different crop farmers in Foulis East Coast Berbice. That is because much of Guyana's agricultural products come from this area. The questionnaires were self-administered, and farmers were selected based on availability.

\section{Soil analysis}

Several tests were done to determine the $\mathrm{pH}$ of the soil, the EC, bulk density, NPK, and organic carbon. NPK test was also done on the worm powder. The soil analysis 
methods (Homer (2003) were used for the lab analyses. The soil $\mathrm{pH}$ gives a good indication of the major chemical reactions in the soil. The $\mathrm{pH}$ can affect several things, including organic and inorganic matter, clay material, and other compounds. The $\mathrm{pH}$ of the soil varies from 4-9. The tests were done at the Biology Lab at the University of Guyana. The $\mathrm{pH}$ and TDS were measured using a $\mathrm{pH}$ tester and TDS meter (Homer 2003). The organic carbon was measured at the Guyana Sugar Inc. Central Laboratory, LBI compound. Organic Carbon by Titrimetry (Walkley and Black Method) was used. Total Kjeldahl Nitrogen in Acid Digests by Spectrophotometry was then done. Next, potassium (K) in Kjeldahl Digests by Flame Photometry was used. This test was also carried out at the Guyana Sugar Inc. Central Laboratory, LBI compound. K was measured using the flame photometer (Homer 2003).

\section{RESULTS AND DISCUSSION}

\section{Results}

In the present research, adult earthworm mortality was considered the endpoint. In addition, the weight change of adult earthworms was also considered to determine the sublethal effects of Urea on the earthworms. The final objective was to determine if there was a significant effect on the reproduction of earthworms exposed to Urea. It was also important to consider the conditions the earthworms had no access to and the other factors that could have affected the mortality of the earthworms. The results obtained are summarized in this section.

Table 1 reflects the chemical properties of soil in different treatments. There was an increase in $\mathrm{pH}$, TDS, NPK, and organic carbon after introducing earthworms to the soil (Control). Adding Urea (T1 to T5) does not affect phosphorous, potassium, and OC. Nitrogen increase was observed from $\mathrm{T} 1$ to $\mathrm{T} 5$ due to an increase in the doses of Urea. $\mathrm{pH}$ decreased from $\mathrm{T} 1$ to $\mathrm{T} 5$, which could be attributed to the nitrification of ammonium-N in Urea that is converted to nitrate, releasing $\mathrm{H}^{+}$ions and causing acidity in the soil. The fluctuation in TDS was also recorded due to changes in urea dosage in different treatments.

The first urea application was made six days after the bins were set up and nine days after the first worm check. The results indicate that the worms were already affected by the Urea. The highest loss at this time was in the control group, as shown in (Table 2); this was because the soil was waterlogged. In the bins treated with Urea, the highest number of death was eight in T2; only one died in T4 and four in T5. It shows that the initial $50 \%$ of Urea had a minor effect on the worms in clay soil. The second application of Urea, $25 \%$, was made two days before the second check for the number of live worms at 30 days. Although the number of live worms in T2 and T5 decreased rapidly, the other groups treated with Urea did not have such a significant loss. The last application of Urea was made after the third check on the $45^{\text {th }}$ day of the experiment; it is noteworthy that there was no significant difference in the number of live worms in each bin from the previous check at this time. The final fertilizer application of $25 \%$ was made one week before the last check on the $60^{\text {th }}$ day. A drastic decrease in the number of earthworms in T5 was observed (Table 2). The treatment groups with lower Urea did not see such a significant number of deaths. In the Urea dose of $250 \mathrm{mg} / \mathrm{kg}$, the earthworms also weakened and ruptured the epidermis, as seen in some indicated in (Figure 1).

The treatment groups had the following dose of Urea, $50 \mathrm{mg} / \mathrm{kg}, 100 \mathrm{mg} / \mathrm{kg}, 150 \mathrm{mg} / \mathrm{kg}, 200 \mathrm{mg} / \mathrm{kg}$ and 250 $\mathrm{mg} / \mathrm{kg}$. There was a variation in the mortality of the earthworms. The control group had a mortality of $30 \%$ at the end of 60 days. Partially this was because one of the replicates was waterlogged; after this was corrected by adding the soil amendment, the number of deaths decreased. In $\mathrm{T} 1$ and $\mathrm{T} 4$, the mortality was very low, reaching over $15 \%$ and $13 \%$ after 60 days. The mortality was higher in $\mathrm{T} 2$ and $\mathrm{T} 3$, reaching $33 \%$ and $32 \%$ in both treatment groups. The highest mortality was in T5, where mortality among the test subjects reached $48 \%$ (Table 3 ).

Table 1. The variation in the soil chemical properties before and after urea treatments

\begin{tabular}{lcccccc}
\hline Treatment & pH & $\begin{array}{c}\text { TDS } \\
(\mathbf{p p m})\end{array}$ & $\begin{array}{c}\text { Total } \\
\mathbf{N} \\
(\boldsymbol{\%})\end{array}$ & $\begin{array}{c}\text { Total P } \\
(\boldsymbol{\%})\end{array}$ & $\begin{array}{c}\text { Total } \\
\mathbf{K}(\boldsymbol{\%})\end{array}$ & $\begin{array}{c}\text { Total } \\
\mathbf{O C} \\
(\%)\end{array}$ \\
\hline Initial sample & 6.3 & 301.00 & 6.10 & 0.60 & 0.01 & 0.08 \\
Control & 8.4 & 413.67 & 6.50 & 0.65 & 0.02 & 0.12 \\
T1 $(50 \mathrm{mg} / \mathrm{kg})$ & 8.2 & 322.33 & 6.57 & 0.64 & 0.02 & 0.12 \\
T2 $(100 \mathrm{mg} / \mathrm{kg})$ & 8.0 & 282.67 & 6.69 & 0.62 & 0.02 & 0.10 \\
T3 $(150 \mathrm{mg} / \mathrm{kg})$ & 7.9 & 310.33 & 6.97 & 0.68 & 0.02 & 0.12 \\
T4 $(200 \mathrm{mg} / \mathrm{kg})$ & 7.8 & 337.33 & 7.14 & 0.67 & 0.02 & 0.11 \\
T5 $(250 \mathrm{mg} / \mathrm{kg})$ & 7.8 & 282.20 & 11.76 & 0.70 & 0.02 & 0.12 \\
\hline
\end{tabular}

Table 2. The number of live adult earthworms under the control and experimental set up during 60 days

\begin{tabular}{lccccc}
\hline Treatment & $\begin{array}{c}\mathbf{1} \\
\text { day }\end{array}$ & $\begin{array}{c}\mathbf{1 5} \\
\text { days }\end{array}$ & $\begin{array}{c}\mathbf{3 0} \\
\text { days }\end{array}$ & $\begin{array}{c}\mathbf{4 5} \\
\text { days }\end{array}$ & $\begin{array}{c}\mathbf{6 0} \\
\text { days }\end{array}$ \\
Control & 60 & 51 & 47 & 46 & 42 \\
T1 $(50 \mathrm{mg} / \mathrm{kg})$ & 60 & 54 & 52 & 52 & 51 \\
T2 $(100 \mathrm{mg} / \mathrm{kg})$ & 60 & 52 & 46 & 42 & 40 \\
$\mathrm{~T} 3(150 \mathrm{mg} / \mathrm{kg})$ & 60 & 55 & 54 & 51 & 41 \\
$\mathrm{~T} 4(200 \mathrm{mg} / \mathrm{kg})$ & 60 & 59 & 54 & 54 & 52 \\
$\mathrm{~T} 5(250 \mathrm{mg} / \mathrm{kg})$ & 60 & 56 & 44 & 44 & 31 \\
\hline
\end{tabular}

Table 3. The percentage mortality of adult earthworms under the control and experimental set up during 60 days

\begin{tabular}{lcccc}
\hline Treatment & $\begin{array}{c}\mathbf{1 5} \text { days } \\
(\boldsymbol{\%})\end{array}$ & $\begin{array}{c}\text { 30 days } \\
(\boldsymbol{\%})\end{array}$ & $\begin{array}{c}\mathbf{4 5} \text { days } \\
(\mathbf{\%})\end{array}$ & $\begin{array}{c}\text { 60 days } \\
(\boldsymbol{\%})\end{array}$ \\
\hline Control & 15 & 22 & 23 & 30 \\
T1 & 10 & 13 & 13 & 15 \\
T2 & 13 & 23 & 30 & 33 \\
T3 & 8 & 10 & 15 & 32 \\
T4 & 2 & 10 & 10 & 13 \\
T5 & 7 & 27 & 27 & 48 \\
\hline
\end{tabular}




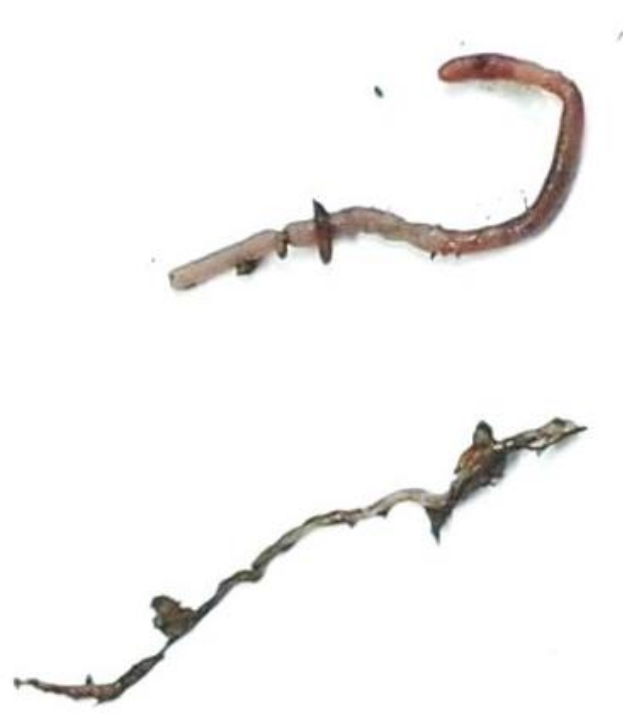

Figure 1. Fragmented body of the dead earthworms under 250 $\mathrm{mg} / \mathrm{kg}$ dose of Urea after 60days

In all treatment groups except T4, the final weight of an individual earthworm was higher than the initial weight. It should be noted that the initial weight is an average weight achieved from weighing 60 earthworms and taking the mean, and the final weight is the weight of the live earthworms at the end of the experiment. The number of earthworms, therefore, varied from each group. The highest weight of a single worm at the end of 60 days was in the control group, which had $1.23 \mathrm{~g}$. The earthworms that weighed the least were in T4, which had $0.82 \mathrm{~g}$ (Table 4).

The first application of Urea was six days after the bins were set up; nine days after the first worm check was done, the results indicated a small number of juveniles in each bin. The second urea application was made two days before the second check at 30 days. At that time, the highest number of juveniles was in the treatment group T5. The treatment groups with a lower dose of Urea did not significantly increase the number of juveniles compared to the first check. However, the number of worms in the control group also increased. At the third check, the number of juveniles in each group decreased approximately a week after the second dose of Urea was applied. The treatment group T5 had the highest mortality at this time. At the final check, the number of juveniles in each group increased; the highest number was seen in the control group, while T5 had the least number of juveniles (Table 5).

As indicated in Table 6, there is a significant difference between the control and treatment groups with Urea when measuring the endpoint, mortality. As the amount of Urea increased, the mortality of earthworms also increased. There was no significant effect on the juveniles; therefore, the urea concentration added to the soil did not affect the mortality of the juveniles.
Table 4. The weight of the earthworms before and after being exposed to Urea and the control group

\begin{tabular}{lcccc}
\hline Treatment & $\begin{array}{c}\text { Number of } \\
\text { live } \\
\text { earthworms }\end{array}$ & $\begin{array}{c}\text { Initial } \\
\text { weight } \\
(\mathbf{g})\end{array}$ & $\begin{array}{c}\text { Final } \\
\text { weight } \\
\text { (g) }\end{array}$ & $\begin{array}{c}\text { Average } \\
\text { weight of one } \\
\text { earthworm } \\
\text { (g) }\end{array}$ \\
\hline Control & 42 & 38.53 & 51.78 & 1.23 \\
T1 & 51 & 38.53 & 55.02 & 1.08 \\
T2 & 40 & 38.53 & 48.93 & 1.22 \\
T3 & 41 & 38.53 & 44.17 & 1.08 \\
T4 & 52 & 38.53 & 42.64 & 0.82 \\
T5 & 31 & 38.53 & 33.32 & 1.07 \\
\hline
\end{tabular}

Table 5. The number of juveniles under the control and experimental set up during 60 days

\begin{tabular}{lcccc}
\hline Treatment & 15 days & 30 days & 45 days & 60 days \\
\hline Control & 7 & 36 & 28 & 78 \\
T1 & 12 & 10 & 39 & 44 \\
T2 & 11 & 23 & 20 & 49 \\
T3 & 5 & 9 & 26 & 57 \\
T4 & 15 & 12 & 13 & 55 \\
T5 & 3 & 45 & 13 & 26 \\
\hline
\end{tabular}

Table 6. Summary of the ANOVA test showing the significant relationship of the data collected on mortality and reproduction ANOVA Two-way $(\mathrm{p}=0.05)$

\begin{tabular}{lcc}
\hline Population characteristics & Treatments & $\begin{array}{c}\text { Time interval } \\
\text { (days) }\end{array}$ \\
\hline $\begin{array}{l}\text { Al } \\
\text { Survival percentage of }\end{array}$ & 0.0045 & $9.90 \mathrm{E}-07$ \\
$\begin{array}{l}\text { Adult worms } \\
\text { Number of Juveniles after }\end{array}$ & 0.0044 & $9.90 \mathrm{E}-07$ \\
60 Days & $0.6316^{*}$ & $4.20 \mathrm{E}-04$ \\
\hline
\end{tabular}

Note: * Not significant

\section{Discussion}

Urea is one of the most common chemical fertilizers used on crop farms in Guyana. The recommended Urea for rice production in Guyana is $36 \mathrm{~kg} / \mathrm{ha}$, but the actual amount used is far higher at $96 \mathrm{~kg} / \mathrm{ha}$ (Moonilall 2015). The amount of Urea recommended for cash crops varies, but this varies depending on the crop type. The misuse of Urea on farms is toxic to soil organisms, including earthworms which are vital to the soil. Earthworms maintain the soil's chemical and physical properties (Rai et al., 2014). Therefore, healthy agricultural soils possess a high concentration of earthworms (Iordache and Borza 2010).

The results obtained from this experiment reveal many interesting facts. Five different concentrations i.e $50 \mathrm{mg} / \mathrm{kg}$, $100 \mathrm{mg} / \mathrm{kg}, 150 \mathrm{mg} / \mathrm{kg}, 200 \mathrm{mg} / \mathrm{kg}, 250 \mathrm{mg} / \mathrm{kg}$ and one control group was set up with replicates of three. The experiment shows that the mortality of earthworms with a dose of $250 \mathrm{mg} / \mathrm{kg}$ was the highest, reaching $48 \%$, as shown in (Table 2). The bodies of the earthworms in this treatment were ruptured, and the live worms were weakened. They 
were not very active and took a long time to burrow into the soil. This observation resonated with what was found by (Rai et al. 2014; Rani 2016). There were also deaths in the other treatments with Urea; T2 and T3 had over $30 \%$ mortality, as shown in (Table 3). The treatment with a low concentration of Urea, T1, had low mortality of adult earthworms, and a large number of castings was observed (Bhattacharya and Kumar Sahu 2014).

The LOEC (Lowest Observed Effect Concentration) was T4 since it had the lowest mortality of 33\%, as shown in (Table 3). The worms in these bins, however, remained at the bottom, and it was observed that a lower number of castings were in these bins compared to other treatment groups. In addition, this group had the earthworms with the lowest weight. The study by (Iordache and Borza 2010) shows similar results in clay soil; there was no significant effect on earthworm mortality at a moderate concentration; however, there were sub-lethal effects such as loss in weight. The weight in all other groups increased, similar to the results by (Rai et al. 2014). There could be two theories for this; first, the bodies of the earthworms exposed to Urea were swollen, so the weight increased. The other theory was that the earthworms were healthy and gained weight (Rai et al. 2014). From observations, the earthworms in the control group were much healthier than those exposed to Urea. There was no significant change in morphology observed in the treatment groups.

The experiment also shows that Urea affects the reproduction of adult earthworms and the mortality of juveniles. After the juveniles were exposed to Urea, their number decreased. The treatment groups with Urea had significantly fewer juveniles than the control group (Table 5). That shows that Urea at any concentration affects juveniles. The treatment with a dose of $250 \mathrm{mg} / \mathrm{kg}$ of Urea had the least amount of juveniles. The earthworms were also small, indicating that they were newly hatched earthworms, and some of them counted before they died. The study carried out by Bhattacharya and Kumar Sahu (2014) had similar results for the mortality of juveniles. It was also observed that the growth of the juveniles was slow; this could be a direct result of their exposure to Urea.

In conclusion, it was determined that Urea at a low concentration is safe for earthworms to survive in clay soil. At a high concentration, the effects of Urea on earthworms are observed by high mortality, negative effects on reproduction as well as the changes in the activity of the earthworms in the soil. It was observed that Urea affects the juveniles at any dose. The mortality of juveniles is proportional to the concentration of Urea. The growth rate of Juveniles is also affected by exposure to Urea. Earthworms burrow into the lower regions of the soil to avoid exposure to Urea.

\section{ACKNOWLEDGEMENTS}

The authors express profound gratitude to the University of Guyana, Turkeyen Campus, and Central Laboratory, Guyana Sugar Corporation, for the facilities and support rendered.

\section{REFERENCES}

Abbirammy K, Ross P. 2013. Determination of Acute Toxicity of Urea to Eisenia Fetida by a simple paper contact method. Intl J Sci Environ Technol 2 (5): 886-891.

Bhattacharya A, Kumar Sahu S. 2014. Lethal effect of Urea on soil biota : a laboratory study on earthworm (Drawida willsi). Journal of Biodiversity and Environmental Sciences (JBES) (4) 6 p. 64-72.

Darwin C. 1881. The formation of Vegetable Mound through the actions of worms with observations on their habits. London: Murray.

Edwards C, Lofty J. 2002. Nitrgenous fertilizers and Earthworms populations in agricultural soils. Soil Biology and Biochemistry 515521.

Homer F. 2003. Soil Analysis Manuel. LBI, Guyana: Central Analytical and Environmental Monitoring Services, Agriculture Research Department.

Iordache M, Borza I. 2010. Relationship between chemical indicies of the soil and earthworm abundance under chemical fertilization. Plant and Soil Environment 401-407.

Moonilall N. 2015. Impact of Amendments on Soil Properity in Guyana. Ohio State University, Ohio.

Ashiya P, Rai N, Rathore DS, Jain S. 2015. Influence of chemical fertilizers and organic fertilizers on ph and available nitrogen content of vermicompost with earthworm Eisenia foetida. Intl J Adv Res 3 (7): 1030-1036.

Rai N, Ashiya P, Rathore DS. 2014. Comparative study on the effect of chemical fertilizers and organic fertilizers on Eisenia foetida. Intl $\mathbf{J}$ Innov Res Sci Eng Technol 3 (5): 12991-12998.

Rani S. 2016. Effect of Urea on soil macro fauna, juvenile earthworms. Haryana, India. J Intl Acad Res Multidisciplinary 4 (5): 15-19.

Tiwari SC. 1993. Effects of Organic Manure and NPK fertilization on earthworm activity in an Oxisol. Biol Fert Soils 16 (4): 293-295.

Valckx JGG. 2011. Optimizing Earthworm Sampling in Ecosystems. In A. Karaca Biology of Earthworms. Springer, Berlin.

World Bank. 2016. Country Overview. Retrieved 01 06, 2017, from Overview of Guyana: www.worldbank.org/en/country/guyana/overview. 